\title{
A FORMAÇÃO INICIAL DO(A) PROFESSOR(A) DE GEOGRAFIA: UM ESTUDO DAS REPRESENTAÇÕES SOCIAIS DO SER PROFESSOR(A)
}

\author{
Cláudia Valéria Rosa da Silva ${ }^{1}$, Rejane Dias da Silva ${ }^{2}$ \\ ${ }^{1}$ Mestra em Educação pela Universidade Federal de Pernambuco - UFPE. Atua na educação básica, no ensino de \\ Geografia. ORCID iD: https://orcid.org/0000-0002-0190-8251 E-mail: claudiavaleria22@hotmail.com. \\ ${ }^{2}$ Doutora em Educação pela Universidade Federal de Pernambuco - UFPE. Atualmente é Professora da Universidade \\ Federal de Pernambuco - UFPE. ORCID iD: https://orcid.org/0000-0003-4125-3883 E-mail: rejanediasilva@gmail.com.
}

\section{RESUMO}

Este artigo apresenta parte dos resultados da pesquisa realizada no mestrado em educação, no qual foram investigadas as representações sociais dos licenciandos(as) de geografia sobre o ser professor(a). Essa pesquisa teve por objetivo compreender as representações sociais dos licenciandos(as) em geografia acerca do ser professor(a) dessa disciplina. Para tal, buscou-se identificar o campo semântico das representações sociais dos licenciandos(as) e a estrutura interna de tais representações. Para alcançarmos os referidos objetivos, tomamos como aporte teórico-metodológico a Teoria das Representações Sociais (MOSCOVICl, 1961), bem como a abordagem estrutural (ABRIC, 1994). Utilizamos como instrumentos de coleta de dados questionário de associação livre de palavras e entrevista semiestruturada. Para análise dos dados, fizemos uso do software Iramuteq e da técnica de análise de conteúdo (BARDIN, 1977). Participaram como sujeitos da pesquisa 149 licenciandos(as) em geografia de duas instituições federais de ensino superior da Região Metropolitana do Recife (RMR). Como resultados encontrados temos as representações sociais dos(as) licenciandos(as) em geografia se inserindo em quatro categorias: disciplinar, pedagógica, afetiva e profissional, sendo a categoria disciplinar e pedagógica as que possuem maior expressividade. Esses resultados não esgotam as discussões acerca das representações sociais do ser professor(a), na realidade são propositivos para o desenvolvimento de novas pesquisas que pensem a respeito da formação inicial do professor de geografia.

Palavas-chave: Formação inicial de Professores - Geografia. Representações Sociais - Licenciandos.

\section{THE INITIAL TRAINING OF THE GEOGRAPHY TEACHER: A STUDY OF THE SOCIAL REPRESENTATIONS OF THE TEACHER}

\section{ABSTRACT}

This article presents part of the results of the research carried out in the master's degree in education, in which the social representations of geography graduates about being a teacher were investigated. This research aimed to understand the social representations of undergraduate students in geography about being a teacher in this discipline. To this end, we sought to identify the semantic field of the social representations of the graduates and the internal structure of such representations. To achieve these objectives, we used the Theory of Social Representations as a theoretical-methodological approach (MOSCOVICl, 1961), as well as the structural approach (ABRIC, 1994). We used as instruments of data collection questionnaire of free association of words and semi-structured interview. For data analysis, we used the Iramuteq software and the content analysis technique (BARDIN, 1977). 149 research subjects in geography from two federal higher education institutions in the Metropolitan Region of Recife (RMR) participated as research subjects. As results found we have the social representations of the undergraduate students in geography falling into four categories: disciplinary, pedagogical, affective and professional, with the disciplinary and pedagogical category having the greatest expressiveness. These results do not exhaust the discussions about the social representations of being a teacher, in reality they are propositional for the development of new researches that think about the initial formation of the geography teacher.

Keywords: Initial Teacher Education - Geography. Social Representations - Graduates. 


\section{LA FORMACIÓN INICIAL DEL PROFESOR DE GEOGRAFÍA: UN ESTUDIO DE LAS REPRESENTACIONES SOCIALES DEL PROFESOR}

\section{RESUMEN}

Este artículo presenta parte de los resultados de la investigación realizada en la maestría en educación, en la que se investigaron las representaciones sociales de los egresados de geografía sobre el ser docente. Esta investigación tuvo como objetivo comprender las representaciones sociales de los estudiantes de pregrado en geografía sobre el ser docente en esta disciplina. Para ello, se buscó identificar el campo semántico de las representaciones sociales de los egresados y la estructura interna de dichas representaciones. Para lograr estos objetivos, utilizamos la Teoría de las Representaciones Sociales como enfoque teóricometodológico (MOSCOVICl, 1961), así como el enfoque estructural (ABRIC, 1994). Se utilizó como instrumentos de recogida de datos el cuestionario de libre asociación de palabras y entrevista semiestructurada. Para el análisis de los datos se utilizó el software Iramuteq y la técnica de análisis de contenido (BARDIN, 1977). 149 sujetos de investigación en geografía de dos instituciones federales de educación superior de la Región Metropolitana de Recife (RMR) participaron como sujetos de investigación. Como resultados encontrados tenemos las representaciones sociales de los estudiantes de pregrado en geografía en cuatro categorías: disciplinaria, pedagógica, afectiva y profesional, siendo la categoría disciplinaria y pedagógica la de mayor expresividad. Estos resultados no agotan las discusiones sobre las representaciones sociales del ser docente, en realidad son proposicionales para el desarrollo de nuevas investigaciones que piensen en la formación inicial del docente de geografía.

Palabras-clave: Formación inicial del profesorado - Geografía. Representaciones sociales - Graduados.

\section{INTRODUÇÃO}

O presente artigo apresenta resultados encontrados na pesquisa realizada no mestrado em educação, na linha de pesquisa formação de professores e práticas pedagógicas, concluído no presente ano de 2020, cujo título é "Ser professor de geografia nas representações sociais dos licenciandos de geografia".

Esse estudo surgiu com base na formação de uma das autoras, licenciada em geografia, que, ao longo de sua trajetória, obteve contato com a geografia escolar, devido a estágios curriculares e à participação no Programa de Iniciação à Docência (Pibid) e no Programa de Iniciação Científica (Pibic). Os debates sobre essas vivências promoveram grande inquietação, pois, ao longo dessa formação, se toma conhecimento de uma geografia que pensa o meio social, que trabalha diversas dimensões da sociedade, mas na escola se apresentava uma geografia tradicional, com ênfase na memorização. Isso acabava por gerar conflito na formação do professor de geografia.

Além disso, ao longo da formação inicial, os licenciandos se deparam com muitos conflitos internos, principalmente em relação às disciplinas de cunho pedagógico, muitos preconceitos estabelecidos quanto à "ineficácia" e ao distanciamento entre a teoria e a prática pedagógica vivenciada na escola.
Um outro ponto a se destacar é o cenário político e cultural do Brasil. Acabamos por nos deparar com um ambiente extremamente complexo.

Santos (2006, p. 9) indica que "vivemos num mundo confuso e confusamente percebido". A geografia pode ser utilizada como uma ciência que nos possibilita compreender as relações sociais que acontecem no espaço geográfico. Dentro do contexto social que vivenciamos, percebemos esse conhecimento sendo colocado em segundo plano, assim como outras áreas do conhecimento humano. Vivemos numa sociedade em que a ênfase se encontra pautada nas ciências exatas e tecnológicas.

Todas essas questões mencionadas nos levaram à seguinte reflexão: o que o(a) licenciando(a) em geografia compreende sobre o ser professor(a) dessa disciplina? Para responder a tal questionamento, compreendemos que a teoria das representações sociais (RS) será um constructo teórico recomendável.

Segundo Moscovici (1961), as representações sociais são conhecimentos do senso comum que norteiam nossas ações e que são transformados e ressignificados ao longo da história. Tais representações também atuam guiando nossas práticas e a organização das sociedades. 
Logo, compreender as representações sociais dos(as) licenciandos(s) de geografia sobre o que é ser professor(a) poderá nos auxiliar a desvelar o significado dessas práticas e o modo como a formação inicial contribui ou não para a construção da identidade do ser professor(a).

Nesse sentido, acreditamos que é necessário estudar os(as) licenciandos(as), compreender o que eles(as) entendem da docência em geografia, já que isso pode vir a possibilitar aos cursos de formação inicial conhecer melhor seus(suas) licenciandos(as), suas angústias, inquietações e necessidades, assim como perceber os aspectos propositivos e as ações que estão contribuindo positivamente para a formação inicial desses futuros professores de geografia. A docência implica sempre conhecer nossos(as) estudantes.

É preciso que, pelo contrário, desde o começo do processo, vá ficando cada vez mais claro que, embora diferentes entre si, quem forma se forma e re-forma ao formar e quem é formado forma-se e forma ao ser formado. É neste sentido que ensinar não é transferir conhecimentos, conteúdos nem formar é ação pela qual um sujeito criador dá forma, estilo ou alma a um corpo indeciso e acomodado. Não há docência sem discência, as duas se explicam e seus sujeitos, apesar das diferenças que os conotam, não se reduzem à condição de objeto um do outro. Quem ensina aprende ao ensinar e quem aprende ensina ao aprender (FREIRE, 2015, p. 25).

Se permitir ouvir e conhecer os(as) licenciandos(as) é um dos passos para a cada dia promover uma formação inicial crítica, reflexiva e que possibilite a esses(as) profissionais formados(as) conhecer o ambiente escolar. Assim, pode-se contribuir para a formação de cidadãos ativos socialmente, cidadãos que são capazes de fazer uma leitura do mundo no qual estão inseridos.
Desse modo, este artigo está estruturado da seguinte forma: primeiro apresentamos o constructo teórico-metodológico que norteou a pesquisa, os procedimentos e análises dos dados; em seguida, abordamos os resultados com as respectivas análises; e, por fim, traçamos algumas considerações finais.

\section{DELINEAMENTO METODOLÓGICO}

Com o propósito de estudar e refletir sobre o objeto de estudo apresentado no decorrer deste texto, compreendemos que a Teoria das Representações Sociais desenvolvida por Moscovici (1961) se apresenta como um recurso teórico-metodológico fortemente recomendável, por viabilizar abordagem multidisciplinar e multifacetada de um fenômeno situado no entrosamento de aspectos sociais e psicológicos que envolvem tanto a dimensão cognitiva quanto afetiva dos sujeitos. Nesse sentido:

Sempre há necessidade de estarmos informados sobre o mundo a nossa volta. Além de nos ajustar a ele, precisamos saber como nos comportar, dominá-lo física ou intelectualmente,

identificar e resolver os problemas que se apresentam: é por isso que criamos representações. Frente a esse mundo de objetos, pessoas, acontecimentos ou ideias, não somos (apenas) automatismos, nem estamos isolados num vazio social: partilhamos esse mundo com os outros, que nos servem de apoio, às vezes de forma convergente, outras pelo conflito para compreendê-lo,

administrá-lo ou enfrentálo. Eis por que as representações são sociais e tão importantes na vida cotidiana. Elas nos guiam, no modo de nomear e definir conjuntamente os diferentes aspectos da realidade diária, no modo de interpretar esses aspectos, tomar decisões 
e, eventualmente, posicionar-se frente a eles de forma decisiva. (JODELET, 2001, p. 17).

De acordo com Chamon, Guareschi e Campos (2014, p. 11): "os sujeitos, coletivamente, constroem a realidade social", nesse processo de construção nascem diferentes representações, que vão abarcar diversos costumes, tradições, espacialidades e temporalidades dos povos que as empreenderam, por isso:

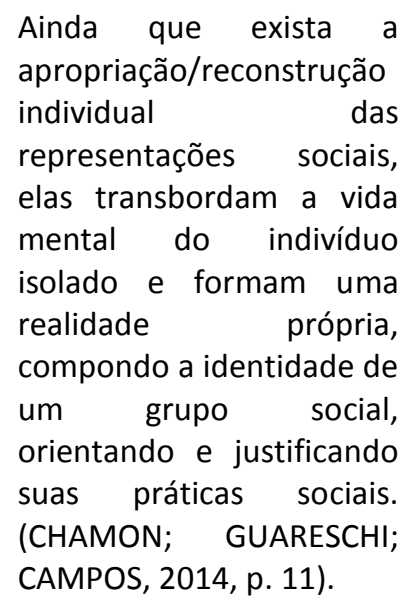

As RS são um construto histórico e espacial, pois elas nascem das relações sociais de um determinado grupo. Toda RS é de alguém para um dado objeto.

$\mathrm{Na}$ presente pesquisa, o objeto de representação social é o "ser professor(a) de geografia", e os sujeitos são os(as) licenciandos(as) em geografia de cursos presenciais de duas instituições federais de ensino superior da Região Metropolitana do Recife (RMR), o Instituto Federal de Educação Ciência e Tecnologia (IFPE) e a Universidade Federal de Pernambuco (UFPE). E a abordagem adotada é a abordagem estrutural cunhada por Jean-Claude Abric (1998).

Desenvolvemos nossa pesquisa em três etapas, utilizando diferentes instrumentos de coleta de dados. Na primeira etapa, desenvolvemos um estudo exploratório, com o objetivo de conhecer os documentos norteadores da licenciatura em geografia. Na segunda etapa, buscamos identificar o campo semântico das RS dos(as) licenciandos(as) em geografia. Procuramos aproximarmo-nos do núcleo central das RS, como propomos em nosso objetivo específico.
Para isso, aplicamos a técnica de associação livre de palavras com os(as) licenciandos(as) em geografia de diferentes períodos do curso $-2^{\circ}, 3^{\circ}, 4^{\circ}, 6^{\circ}$ e $8^{\circ}$ períodos. Foram ouvidos, no total, 148 licenciandos(as) em geografia, sendo 82 da UFPE e 66 do (IFPE).

Os(as) licenciandos(as) que participaram da pesquisa foram aqueles(as) que cursavam a licenciatura em geografia nos campi acadêmicos da cidade do Recife nas instituições referidas e que se dispuseram a contribuir com o andamento do estudo. A escolha pela realização da técnica de associação livre de palavras é fruto do aporte teórico-metodológico que adotamos, considerando que essa técnica possui as seguintes características:

O caráter espontâneo portanto menos controlado - e a dimensão projetiva dessa produção deveriam, portanto, permitir o acesso, muito mais fácil e rapidamente do que em uma entrevista, aos elementos que constituem o universo semântico do termo ou do objeto estudado. Associação livre permite a atualização de elementos implícitos ou latentes que seriam perdidos ou mascarados nas produções discursivas. (ABRIC, 1994, p. 66 apud SÁ, 1998, p. 92).

A técnica de associação livre de palavras foi efetuada da seguinte forma: solicitamos que os(as) licenciandos(as) citassem seis palavras sobre as quais a expressão "ser professor(a) de geografia" os(as) faz pensar. Em seguida, pedimos que destacassem, dentre as seis palavras citadas, a que melhor definiria "ser professor(a) de geografia". A técnica de associação livre de palavras permite o andamento da pesquisa, ao passo que nos possibilita obter informações aprofundadas dos sujeitos de pesquisa, de modo espontâneo.

Aplicamos essa técnica em forma de questionário, já que buscamos também conhecer o perfil dos(as) licenciandos(as) em geografia das instituições de ensino já referidas, pois partimos da compreensão de que as representações sociais se constituem como um construto histórico e social: 
Ainda que exista a apropriação/reconstrução individual das representações sociais, elas transbordam a vida mental do indivíduo isolado e formam uma realidade própria, compondo a identidade de um grupo social, orientando e justificando suas práticas sociais. (CHAMON; GUARESCHI; CAMPOS, 2014, p. 11).

Ou seja, as RS se constroem ao longo do tempo histórico, em uma espacialidade, e por isso passam por transformações. Assim, faz-se necessário para conhecermos essas representações buscarmos apreender aspectos sociais dos nossos sujeitos de pesquisa.

Portanto, nosso questionário foi composto por duas etapas. A primeira visava conhecer o perfil dos licenciandos. Para isso buscamos saber sexo, idade, se trabalha e, se sim, em qual área. A segunda etapa constituiu-se de duas questões que compunham 0 questionário de associação livre de palavras: na primeira, solicitávamos que os(as) licenciandos(as) citassem seis palavras sobre as quais a expressão "ser professor(a) de geografia" o(a) faziam pensar; na segunda, pedíamos que o(a) licenciando(a), dentre as palavras que escreveu, identificasse a que melhor define ser professor(a) de geografia.

Essa técnica nos possibilitou entrar em contato com o campo semântico das representações sociais, e consequentemente identificar as estruturas internas e o núcleo central das RS do ser professor(a) de geografia, mediante o tratamento e análise dos dados. Para o tratamento dos dados coletados no questionário de associação livre de palavras, utilizamos o software Iramuteq:

Este programa informático viabiliza diferentes tipos de análise de dados textuais, desde aquelas bem simples, como a lexicografia básica (cálculo de frequência de palavras), até análises multivariadas

(classificação hierárquica descendente, análises de similitude). Ele organiza a distribuição do vocabulário de forma facilmente compreensível e visualmente clara (análise de similitude e nuvem de palavras). (CAMARGO; JUSTO, 2013, p. 515).

O Iramuteq propicia acesso à lexicografia, gerando um cálculo de frequência de palavras. Sendo assim, o software gerou o campo semântico, com base nos dados coletados através do questionário de associação livre de palavras.

Mas, além do citado questionário, também realizamos entrevistas semiestruturadas, visando analisar as estruturas internas das RS do "ser professor(a) de geografia".

No presente artigo, apresentamos resultados alcançados em oito entrevistas que foram distribuídas contemplando grande parte dos períodos nos quais aplicamos o questionário. A escolha dos(as) participantes da entrevista deuse primeiro pela vontade de contribuir com a pesquisa demonstrada por parte dos sujeitos, mas também de modo a contemplar grande parte dos períodos nos quais aplicamos o questionário.

Apesar de não termos entrevistas de estudantes de todos os períodos, alcançamos grande parte dos semestres dos cursos. Destacamos que, no momento da realização da pesquisa, solicitamos que os(as) licenciandos(as) escolhessem nomes relacionados à ciência geográfica para identificá-los ao longo do trabalho, como dispomos a seguir: Lua $\left(3^{\circ}\right.$ período/UFPE); Carioca $\left(3^{\circ}\right.$ período/UFPE); Espaço $\left(3^{\circ}\right.$ período/UFPE); Aurora $\left(6^{\circ}\right.$ período/UFPE); Viajante $\left(2^{\circ}\right.$ período/IFPE); Talvegue ( $6^{\circ}$ período/IFPE); Psicosfera $\left(7^{\circ}\right.$ período/IFPE); Esmeralda ( $7^{\circ}$ período/IFPE).

Para análise das entrevistas e dos dados coletados mediante a associação livre de palavras, utilizamos a análise de conteúdo categorial de Bardin (1977):

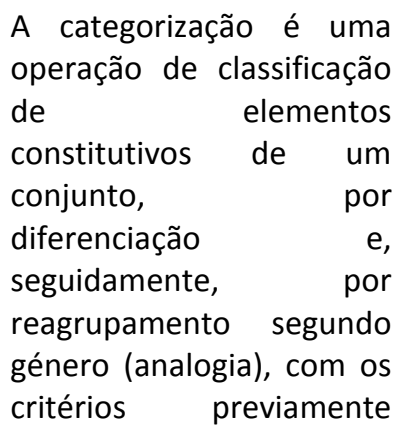


definidos. As categorias são rubricas ou classes, as quais reúnem um grupo de elementos (unidades de registro, no caso da análise de conteúdo) sob um título genérico, agrupamento esse efetuado em razão dos caracteres comuns destes elementos.

(BARDIN, 1977, p. 117).

Dessa forma, primeiramente classificamos os elementos e em seguida os diferenciamos segundo suas características. $\mathrm{Na}$ seção seguinte, iremos explanar justamente os dados alcançados mediante esse processo.

\section{RESULTADOS E DISCUSSÃO}

Após a aplicação do questionário de associação livre de palavras, todas as palavras associadas à expressão-estímulo "ser professor(a) de geografia" foram tabuladas para traçarmos o campo semântico das representações sociais dos(as) licenciandos(as) em geografia. Realizamos esse procedimento mediante a digitação de todas as palavras elencadas no computador, para, então, submetermos as palavras associadas à análise estatística do software Iramuteq.

No momento de apuração das frequências das palavras, escolhemos agrupar palavras sinônimas e mantivemos a palavra que possuía o maior número de frequência. Nesse momento, apresentamos os resultados encontrados para a expressão-estímulo "ser professor(a) de geografia". Foram associadas 837 palavras, das quais 299 se constituíram hápax ${ }^{1}$, ou seja, palavras que foram mencionadas uma única vez.

O campo semântico apresentado abaixo é composto das palavras mais evocadas, que tiveram frequência igual ou superior a 3. A frequência das palavras é indicada na coluna ao lado. O campo semântico apresentado também mostra a categorização das palavras mencionadas.

A categorização foi realizada através da classificação analógica das palavras, além disso, no momento em que realizamos a entrevista semiestruturada, buscamos compreender em que perspectiva algumas palavras foram elencadas.
À medida que íamos inventariando as palavras associadas, fomos percebendo um campo semântico que possui elementos que Tardif (2014) elenca como saberes que corroboram a constituição do docente. Assim, também levamos em consideração os saberes docentes elencados por Tardif (2014) para a formação de nossas categorias: disciplinar, pedagógica, afetiva e profissional.

O campo semântico abaixo encontra-se legendado de forma a deixarmos clara a leitura. Legendamos da seguinte forma: a categoria pedagógica está enumerada com o número 1 , a afetiva com 2, a disciplinar com 3 e a profissional com 4.

\footnotetext{
${ }^{1}$ Palavra ou expressão utilizada pelo software Iramuteq para a palavra sobre a qual só exista um único registro.
} 
Tabela 1. Campo semântico - palavras associadas pelos(as) licenciandos(as) à expressão ser professor(a) de geografia com frequência superior ou igual a 3

\begin{tabular}{|c|c|c|c|}
\hline Palavras Associadas & $\mathbf{F}$ & $\begin{array}{l}\text { Palavras } \\
\text { Associadas }\end{array}$ & $\mathbf{F}$ \\
\hline Conhecimento (3) & 34 & Visão (4) & 4 \\
\hline Amor (2) & 33 & Respeito (2) & 4 \\
\hline Educação (1) & 29 & Meio (3) & 4 \\
\hline Crítico (3) & 25 & Liberdade (2) & 4 \\
\hline Espaço (3) & 24 & Inteligente (1) & 4 \\
\hline Ensinar (1) & 23 & Humano (3) & 4 \\
\hline Aprendizado (1) & 21 & Determinação (2) & 4 \\
\hline Reflexivo (1) & 19 & Cultura (1) & 4 \\
\hline Mundo (3) & 18 & Compromisso (4) & 4 \\
\hline Desafio (4) & 15 & Clima (3) & 4 \\
\hline Dedicação (2) & 14 & Ciência (3) & 4 \\
\hline Sociedade (3) & 14 & $\begin{array}{l}\text { Responsabilidade } \\
\text { (4) }\end{array}$ & 4 \\
\hline Coragem (2) & 10 & Prática (1) & 4 \\
\hline Felicidade (2) & 9 & Coletividade (2) & 4 \\
\hline Realidade (4) & 8 & Auxiliador (1) & 4 \\
\hline Natureza (3) & 8 & Compreensão (1) & 3 \\
\hline Mediador (1) & 8 & Cidadania (1) & 3 \\
\hline Empatia (2) & 7 & Mudança (2) & 3 \\
\hline Educador (1) & 7 & Globalização (3) & 3 \\
\hline Paciência (2) & 6 & Estresse (2) & 3 \\
\hline Estudo (3) & 6 & Escola (1) & 3 \\
\hline Ambiente (3) & 6 & Dinâmica (1) & 3 \\
\hline Terra (3) & 6 & Realização (2) & 3 \\
\hline Construção (1) & 5 & Pesquisador (1) & 3 \\
\hline Trabalho (4) & 5 & Sabedoria (3) & 3 \\
\hline Política (3) & 5 & Resiliente (2) & 3 \\
\hline $\begin{array}{l}\text { Interdisciplinaridade } \\
\text { (1) }\end{array}$ & 5 & Troca (1) & 3 \\
\hline Humanidade (3) & 5 & Transmissão (1) & 3 \\
\hline Futuro (4) & 5 & Transformação (2) & 3 \\
\hline Persistência (2) & 5 & Território (3) & 3 \\
\hline Criatividade (1) & 5 & $\operatorname{Ser}(2)$ & 3 \\
\hline
\end{tabular}

Categorias: Pedagógica (1), Afetiva (2), Disciplinar (3), Profissional (4).

Fonte: As autoras.

Nota: Palavras associadas no Questionário de Associação Livre de Palavras (2019).

$\mathrm{Na}$ categoria disciplinar, agrupamos as palavras que se relacionam com os saberes reconhecidos e identificados como pertencentes ao campo do conhecimento geográfico, assim como a outras áreas do conhecimento. Sendo assim, compõem essa categoria palavras como "conhecimento", pois, nas falas dos(as) licenciandos(as), percebemos que eles(as) expressam a importância dos conhecimentos da ciência geográfica para o ser professor(a) de geografia:

[...] eu consigo enxergar a geografia na física, na questão do movimento, na biologia também, nos biomas, matemática na 
geografia com a economia, e outros números população, natalidade, mortalidade, essas coisas que a gente consegue absorver ainda no ensino fundamental. (Espaço, $4^{\circ}$ período da licenciatura em geografia da UFPE, 2019).

A categoria disciplinar também agrupa palavras como "espaço", categoria basilar da ciência geográfica, "ambiente", "terra", assim como demais palavras, como podemos visualizar no campo semântico.

Outra categoria que emerge do nosso campo semântico é a categoria pedagógica, que comporta palavras das quais emergem sentidos ligados à prática pedagógica: "ensinar", "aprendizado", "mediador" etc.

A categoria afetiva também emerge do campo semântico. Ela comporta palavras que envolvem as relações interpessoais da docência, assim como os sentimentos que os(as) licenciandos(as) atribuem ao ser professor(a) de geografia. Sendo assim, essa categoria possui palavras como: "amor", "empatia" e "felicidade", entre outras.

$E$, por fim, a quarta categoria que emerge do campo semântico é a profissional, composta por elementos do campo profissional da docência. As palavras que compõem esse campo são: "trabalho" e "desafio", entre outras.

Com base na análise e categorização do campo semântico, identificamos que as representações sociais do ser professor(a) de geografia se alicerçam na dimensão disciplinar e pedagógica como podemos identificar com o gráfico abaixo, que torna visível o percentual de cada categoria destacada no campo semântico. A categoria disciplinar e pedagógica possuem cerca de $34 \%$, categoria afetiva com $21 \%$, e profissional com $11 \%$.

Gráfico 1. Percentagem das categorias nas palavras associadas pelos(a) licenciandos(as) à expressão "ser professor(a) de geografia" com frequência superior ou igual a 3

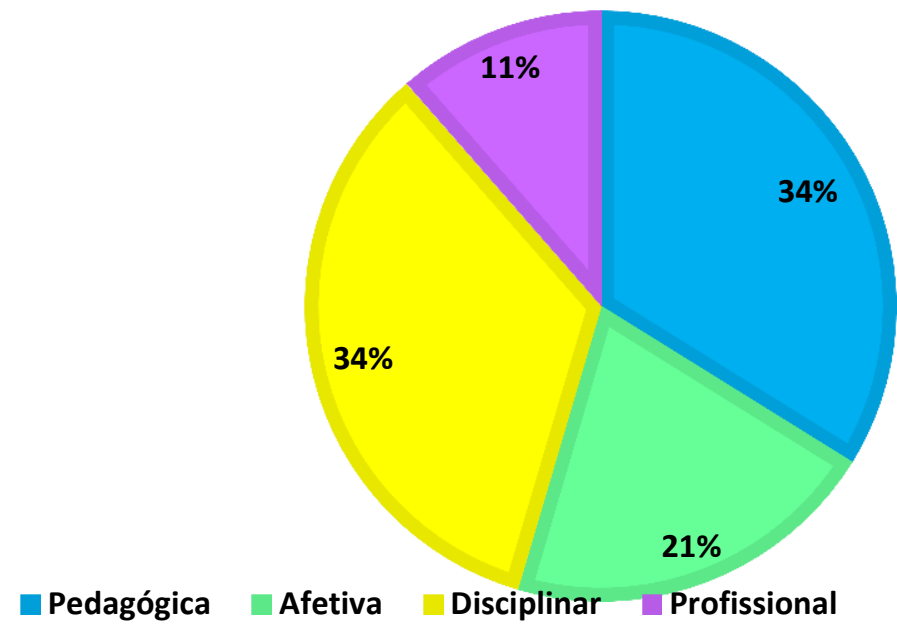

Fonte: As autoras.

Nota: Palavras associadas no Questionário de Associação Livre de Palavras (2019).

O resultado do campo semântico permite-nos inferir que as representações sociais dos(as) licenciandos(as) em geografia são envoltas na categoria disciplinar, e na categoria pedagógica. Esse resultado encontra-se bastante ligado aos dispositivos legais que regem a formação de professores no Brasil, como podemos ver na Resolução, a № 2, de 10 de julho de 2015, que passou a definir as Diretrizes Curriculares Nacionais para a formação inicial de professores em nível superior dos cursos de licenciaturas diversas, dos cursos de formação pedagógica e para a formação continuada.

Essa resolução detalha diversas atribuições para as instituições de ensino superior, desde a formação inicial até a formação continuada de profissionais da educação, preconizando que as instituições devem seguir as Diretrizes Curriculares Nacionais. No $\S 10$ do 
artigo 2으, podemos identificar a concepção de docência que a resolução traz:

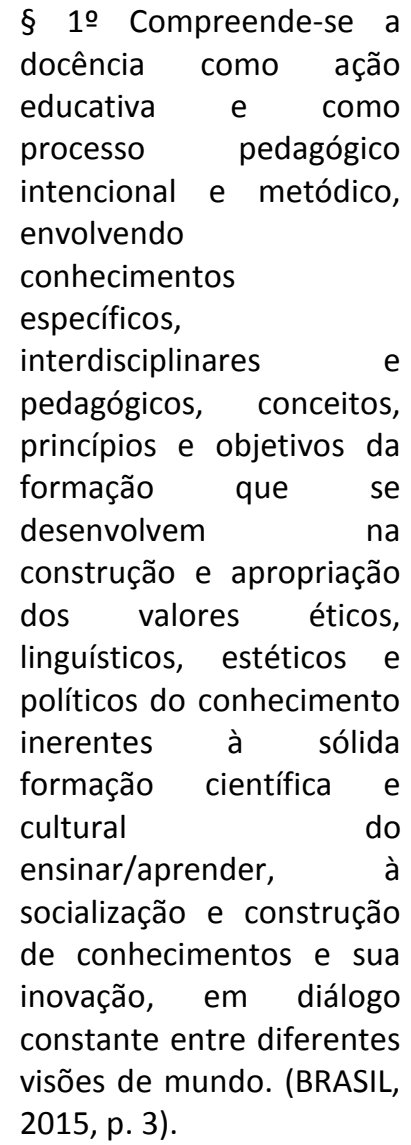

Percebe-se aí que a formação de professores já não é vista apenas como uma formação bacharelesca. A formação inicial, assim como a continuada, é pensada como um processo que envolve os saberes específicos tidos como disciplinares, ou seja, aqueles conhecimentos da ciência basilar da licenciatura, como os saberes geográficos, que podemos ver na licenciatura em geografia. Mas, ao mesmo tempo, devem também ser considerados na licenciatura saberes pedagógicos, princípios de formação humana, saberes políticos e saberes culturais, de forma a desenvolver a criticidade, algo essencial para a formação humana e profissional.

Dada a natureza do trabalho docente, que é ensinar como contribuição ao processo de humanização dos alunos historicamente situados, espera-se da licenciatura que desenvolva nos alunos conhecimentos e habilidades, atitudes e valores que lhes possibilitem permanentemente irem construindo seus saberesfazeres docentes a partir das necessidades e desafios que $o$ ensino como prática social lhes coloca no cotidiano. Espera-se, pois, que mobilize os conhecimentos da teoria da educação e da didática necessários à compreensão do ensino como realidade social, e que desenvolva neles a capacidade de investigar a própria atividade para, a partir dela, constituírem e transformarem os seus saberes-fazeres docentes, num processo contínuo de construção de suas identidades como professores. (PIMENTA, 2005, p. 18).

Dos cursos de licenciatura, onde ocorre a formação inicial dos professores, é cobrada a formação de profissionais que saibam lidar com a realidade escolar, ou seja, professores que consigam mobilizar os saberes acadêmicos e práticos da profissão docente, podendo, assim, contribuir para a formação humana dos estudantes. De um professor de geografia é cobrado que tenha capacidade de mobilizar os saberes da ciência geográfica, isso de forma didática que permita ao discente da educação básica compreender e construir seu saber.

Dessa forma, seguindo os dispositivos legais e o conhecimento científico acerca da formação dos professores, encontramos o currículo do curso de licenciatura em geografia sendo composto por saberes disciplinares, assim como por saberes pedagógicos, já que, desde o primeiro período do curso, os licenciandos começam a trabalhar esses saberes concomitantemente.

Um outro dado que nos chama a atenção é a pouca representatividade da categoria profissional. Essa categoria abarca o conjunto de saberes baseados nas ciências e na erudição, transmitidos aos professores durante o processo de formação. Trata-se de representações da profissão, considerando que os licenciandos compreendem que são professores em formação. Essa categoria não possuiu uma grande 
expressividade como a disciplinar e a pedagógica. Acreditamos que isso se deve ao fato de que:

A profissionalidade constrói-se de forma progressiva e contínua, baseia-se no desenvolvimento de competências e da identidade profissional, inicia-se na profissionalização e prolonga-se ao longo de toda a carreira, sendo, por isso, um processo que permite aos professores apropriarem-se "das práticas, da cultura e dos valores da profissão" (TARDIF; FAUCHER, 2010, p. 35 apud MORGADO, 2011, p. 798).

Uma vez que o conceito de profissionalidade docente abrange todo o processo de transformações que o(a) professor(a) vivencia ao longo de sua profissão, entendemos que a docência tem início já na formação inicial. E vai se se aprimorando com as práticas vivenciadas ao longo dessa formação, assim como posteriormente, ou seja, nas diferentes relações sociais que o(a) professor vivencia e nas múltiplas demandas e condições de realização da docência que o(a) profissional enfrenta.

A categoria afetiva, apesar de possuir um baixo índice, ainda possui expressividade. Isso se encontra muito ligado à história de vida dos(as) licenciandos(as). Muitos(as) dos(as) que participaram da pesquisa destacaram que ser professor(a) é a realização de um sonho de criança, pois a escola era o local de felicidade de sua infância. Outros(as) compreendem que o papel da escola e do professor vai além da transmissão de conhecimento erudito, pois a educação é um lócus de construção do ser humano, portanto, local de humanização.

Mediante o campo semântico, o software Iramuteq gerou a árvore de similitude, que corrobora identificarmos não só as categorias disciplinar, pedagógica, afetiva e profissional, como também compreender a imbricação das palavras, suas correlações e oposições.

Figura 3. Árvore de Similitudes

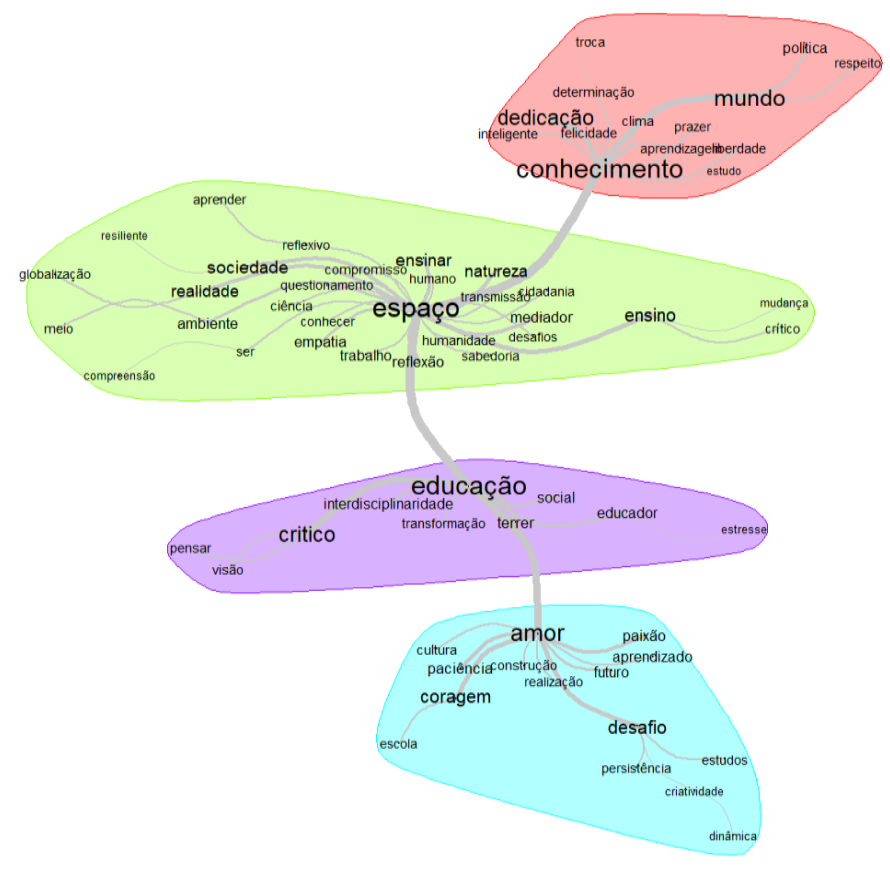

Fonte. As autoras.

Nota: Árvore de similitude, das palavras associadas no Questionário de Associação Livre de Palavras (via Iramutec, 2019).

A palavra "amor" no campo semântico possuiu uma frequência de 33. Podemos ver claramente na árvore de similitude destacada no grupo de palavras demarcadas de azul. Nesse grupo de palavras, podemos ver que a palavra "amor" se encontra atrelada a palavras como 
"paciência", "realização" e "construção". Seguindo a ramificação, encontramos "desafio" e "persistência".

Ao analisarmos a árvore de similitudes em conjunto com as entrevistas realizadas, onde encontramos os(as) participantes da pesquisa justificando suas palavras mencionadas, assim como os motivos que os(as) levaram a realizar a licenciatura, identificamos que a ligação dessas palavras é legitima:

[...] quando eu comecei a trabalhar no mercado formal eu tive que deixar porque eu não tive mais tempo de fazer o reforço, aí eu tive que me apegar muito ao trabalho, e no trabalho veio muito aquela coisa da vontade de casar, e tal e as coisas a nível de graduação foram ficando para trás, fui buscando aquisição das minhas coisas, aí veio filho e tal, então aí acabei deixando o sonho de ser professora que eu sempre tive para trás, ainda tentei vestibular ali quando eu comecei a trabalhar, queria fazer muitas vezes para Letras na Federal, mas era outro cenário que não favorecia os jovens da educação pública né, porque a disputa era acirrada, em toda minha vida por onde eu passei, quando eu estudava história e geografia eu me encantava, meu pai conseguia comprar meus livros né, as compras dos livros era sempre anual, no mês de janeiro, eu lembro como se fosse hoje, eu ia com ele, que ele fazia questão de me levar, e os livros de geografia e história era os primeiros que eu pegava, me encantava a questão dos mapas, me encantava saber que aquele mundo todo gigante, grande, estava dentro de um planeta, que estava dentro de um cenário de um universo, era fantástico pra mim. (Psicosfera, licencianda do $7^{\circ}$ período, do IFPE, 2019).

O trecho acima da entrevista realizada com a licencianda em geografia do $7^{\circ}$ período do IFPE permite-nos conhecer um pouco do seu trajeto de vida e perceber que a escolha por cursar a licenciatura em geografia está ligada a uma questão emocional e profissional, pois percebe-se uma ligação afetiva tanto com a geografia quanto com a profissão docente. Mas as experiências de vida da licencianda Psicosfera não foram propositivas para o ingresso no curso ainda em sua juventude. Assim, hoje aos 47 anos, a licencianda consegue cursar a licenciatura e realizar dessa forma um sonho pessoal e profissional.

Assim palavras como "amor", "paciência", "realização", "construção", "desafio" e "persistência" realmente são próximas e inserem-se na categoria afetiva e profissional. Isso nos indica que a licenciatura em geografia, para alguns(as) licenciandos(as), possui uma forte carga emocional e de realização profissional. Isso nós identificamos também com o licenciando Carioca, do $3^{\circ}$ período da licenciatura em geografia, da UFPE, quando conhecemos um pouco de sua trajetória de vida:

Bom minha trajetória é na verdade eu iniciei na Universidade Federal de Pernambuco em 1992, no curso de geografia, eu passei na época no curso antigo, e cursei até 96 , e infelizmente por problemas pessoais eu não concluí o curso, que antigamente era os 2 bacharelado e licenciatura juntos, eu tive alguns problemas pessoais, de problema depressivos, então eu ainda jovem eu entrei aqui com 17 anos né, era bem, bem, bem jovem, e assim, eu não tive um arcabouço familiar e tudo pra poder persistir e terminar, ficou faltando só TCC, aquela coisa toda, e abandonei, e fui pra trabalhar em outro mundo. Nunca dei aula, não trabalhei na área de 
geografia, infelizmente, apesar de amar, e ser apaixonado por natureza, tudo, geografia, tudo, cartografia etc., mas infelizmente segui por outro caminho, e quando eu retornei a Recife, porque em 96 eu fui morar no Sudeste do país, no Rio, e depois em São Paulo, aí eu tive já oportunidade de voltar a Recife em 2015 e, por coincidência, eu vim me alocar aqui na Iputinga, depois, Engenho do Meio, e ficava aquela coisa toda, eu já trabalhando, normal, eu trabalho com vendas né, representante comercial, aí sempre passando, e passando na frente da Universidade, e eu olhava, e gente eu não acredito que não concluí meu curso né, passava olhava o $\mathrm{CFCH}$ imponente lá no fundo. (Carioca, licenciando do $3^{\circ}$ período, da UFPE, 2019).

Assim como a licencianda Psicosfera, o licenciando Carioca, mediante questões de cunho pessoal, não concluiu o curso de geografia em sua juventude. E passados cerca de 23 anos, ele atualmente vem cursando a licenciatura em geografia.

Percebe-se na história de vida desses licenciandos todo um amor pela docência, assim como pela ciência geografia. E foi justamente esse sentimento que levou ambos a persistirem e enfrentarem os desafios da vida e hoje poderem cursar a licenciatura em geografia. Assim, compreendemos um pouco como as palavras da árvore de similitude encontram-se correlacionadas.

Se analisarmos o grupo destacado de lilás na árvore de similitude, identificaremos as seguintes palavras: "educação", "crítico", "interdisciplinaridade", "social", "educador" e "estresse" (vocábulos em que o campo semântico destaca suas frequências). A correlação dessas palavras explica-se tanto nas respostas encontradas ao longo das entrevistas que realizamos, como veremos, como também por Vesentini (2008) e outros autores já discutidos ao longo do trabalho, que deixam claro que a educação é um processo complexo, composto por diferentes saberes, valores e anseios sociais:

Mas a escola não é apenas uma instituição indispensável para a reprodução do sistema. Ela é também um instrumento de libertação. Ela contribuiu - em maior ou menor escala, dependendo de suas especificidades - para aprimorar ou expandir a cidadania, para desenvolver o raciocínio, a criatividade e o pensamento crítico das pessoas, sem os quais não se constrói qualquer projeto de libertação, individual ou coletivo. (VESENTINI, 2008, p. 16).

Podemos identificar com Vesentini (2008) uma compreensão de que o ambiente escolar deve ser palco de uma educação que promova a cidadania e o pensamento crítico. Sendo assim, o ato educativo implica em criticidade, transformação, em pensar o meio social. Isso é identificado também na fala de Espaço, do $4^{\circ}$ período da UFPE:

Como professor, atualmente me vejo na obrigação de acrescentar ao imaginário do alunado, o que tem de mais amplo, a nossa realidade, trazer essa realidade que é sublimada por banners por paisagens artificiais, ou letreiros, trazer a questão o que tá ali, o que essas pessoas contribuem para aquela paisagem todo dia, e como aquela paisagem contribui para essas pessoas todo dia, é uma troca também, se é uma troca do aluno e do professor, também é uma troca do indivíduo com o meio, também é chamando atenção para essa parte ecológica, que a gente tem que tá preservando o planeta, que somos as novas 
gerações e vamos deixar descendentes, e creditando a juventude, dando crédito a ela, que é ela que vai fazer ciência, eu tô aqui nessa posição agora, mas eu estava lá há pouco tempo atrás e enquanto eu era aluno não tive essa visão ou esse espaço para debater sobre essas coisas. Eu acho interessante o professor estreitar o laço que tem, inclusive não ser só 0 professor que chega, fala e vai embora, mas ser o professor que chega, conhece, aprende, vai embora, mas volta, volta com mais, e vai embora também com mais, com mais do que quando chegou. (Espaço, $4^{\circ}$ período da licenciatura em geografia, da UFPE, 2019).

$O$ ato de educar, assim, acaba por se efetuar mediante a criticidade, pela ação do professor de buscar nos educandos uma percepção do mundo que os rodeia. E mediante a leitura de mundo, o pensar em conjunto, a sociedade vai se transformando. Mas onde entra o estresse que se encontra inserido no grupo lilás da árvore de similitude? Se pararmos para analisar os espaços em que o ato educativo vem se realizando, essa palavra acaba por fazer total sentido dentro desse grupo. Quando questionamos a licencianda Aurora acerca do que ela compreendia a respeito do ser professor(a) de geografia, ela elencou:

Resistir né, principalmente quando se aborda a questão geopolítica porque a gente tá vivendo uma conjuntura política onde há um plano de uma escola sem partido, que é falado aí há anos já, e tramita, enfim, isso foi superado no passado, mas é sempre recorrente, dentro da conjuntura que a gente tá vivendo, e o professor de geografia ele não ter esse papel político, porque a gente cumpre um papel político também enquanto professor de geografia, é bem complicado, é complexo, é difícil, por isso a palavra que eu acho que define é resistência mesmo em sala de aula, para que os professores consigam exercer bem a atividade, o exercício da docência. (Aurora, licencianda do $6^{\circ}$ período da UFPE, 2019).

Podemos identificar com a fala de Aurora que o contexto sociopolítico do Brasil afeta a prática docente. Pimenta (2005, p. 18) esclarece isso mediante o fato de que a "profissão de professor, como as demais, emerge em dado contexto e momento históricos, como resposta a necessidades que estão postas pelas sociedades, adquirindo estatuto de legalidade". Sendo assim, já que a profissão docente emerge do contexto social, ela vai carregar consigo as demandas e as crises que a sociedade vivencia. Tudo isso acaba por promover estresse.

Além dessa questão, ainda temos o fato de que grande parte das escolas possui um ambiente de trabalho estressante, por conta das carências encontradas e bem mencionadas pelo licenciando do $8^{\circ}$ período de geografia, Talvegue, quando questionado acerca dos desafios que o docente encontra:

Um dos desafios que me deparei no estágio é uma sala com muitos estudantes, um ambiente que não é muito propício, em uma escola que fiz estágio no Cabo, a linha do trem era ao lado da escola. A sala não era propícia, só funcionava um ventilador, o barulho do trem ainda atrapalhava, ainda tem o pouco tempo da aula, então você administrar tudo isso é difícil, também um desafio é trabalhar geografia de uma forma diferente porque você muda e traz outros elementos para a aula e os alunos não estão acostumados (Talvegue, licenciando do $8^{\circ}$ período do IFPE, 2019). 
O ambiente de trabalho sem infraestrutura adequada, em conjunto com salas de aula superlotadas, o tempo de aula de geografia de apenas duas aulas por semana, aulas essas que muitas vezes não são geminadas, e um grande número de conteúdos a serem trabalhados ao longo do ano letivo afetam o desenvolvimento da aula e ocasionam também estresse.

Então, percebemos que esses(a) licenciandos(as), apesar de possuírem a percepção de que a educação geográfica deve ser crítica, de modo a propiciar visão de mundo, para que os discentes se percebam como seres sociais, cidadãos que possuem deveres e direitos, acabam por sofrer ainda no seu curso de formação inicial com o estresse, diante das dificuldades de colocar em prática o que eles(as) acreditam ser sua função.

Partindo para analisar o grupo destacado em verde na árvore de similitude, deparamo-nos com os saberes disciplinares que compõem a licenciatura em geografia. Emergiram palavras como: "espaço" (objeto de estudo da geografia), "humanidade", "globalização", "meio" e "natureza", mas, além destas, cujas frequências são descritas no campo semântico, encontramos também vocábulos como "ensino", "conhecer", "aprender" e "reflexivo". Agregando essas palavras aos dados encontrados nas entrevistas, identificamos que os(as) licenciandos(as) em geografia percebem que os saberes disciplinares são basilares para sua formação, mas que a docência se encontra ligada ao ato de ensinar, refletir, aprender e conhecer. Ou seja, os saberes disciplinares encontram-se relacionados com os saberes pedagógicos.

Dessa forma, a docência é um complexo conjunto de saberes. Identificamos isso claramente quando questionamos os(as) licenciandos(as) sobre o que compreendem acerca do ser professor(a) de geografia:

É contribuir, pra que mais pessoas consigam ter esclarecimento das coisas, consigam atingir uma percepção que é extremante necessária para a gente construir um mundo mais harmonioso, sabe, a questão da relação do homem com o homem, do homem com o espaço, com a natureza, então eu quero muito contribuir para isso, mesmo que seja numa escala pequena, na comunidade, mas eu quero acordar todo dia de manhã e ir dormir todo dia consciente que minhas palavras, que o que eu repasso vai contribuir para isso. É uma gotinha no meio do oceano né, mas é uma gotinha. (Psicosfera, licencianda do $7^{\circ}$ período do IFPE, 2019).

A licencianda Psicosfera esclarece-nos que a docência, na sua concepção, é contribuir para que os(as) discentes(as) compreendam os saberes geográficos e, através esses saberes, possam construir uma sociedade harmoniosa. Esse pensamento é feito tanto pela licencianda do $7^{\circ}$ período, quanto pelo licenciando Viajante do $2^{\circ}$ período do IFPE: "Para mim ser professor de geografia não é muito diferente de ser professor em geral, que é saber repassar para os alunos e para as próximas gerações algo que me foi ensinado". Ou seja, o ser professor(a) de geografia encontra-se atrelado ao ato de ensinar os saberes disciplinares da geografia.

Como Freire $(2015$, p. 25) afirma: "Ensinar inexiste sem aprender e vice-versa, e foi aprendendo socialmente que, historicamente, mulheres e homens descobriram que era possível ensinar". Sendo assim, o ser professor(a) de geografia está intrinsecamente ligado ao ato de aprender e ensinar.

$\mathrm{Na}$ licenciatura em geografia, aprender e ensinar é permeado de saberes sociais, como identificamos no grupo destacado de rosa na árvore de similitude. Emergiram palavras como: "mundo", "política", "respeito", vocábulos que se encontram muito próximos no canto superior esquerdo. Mas esses saberes sociais só surgem mediante o conhecimento que é produzido socialmente. E a aquisição desses saberes demanda: "dedicação", "inteligência", "estudo", "prazer" e "determinação", ou seja, os saberes que compõem a licenciatura em geografia são saberes provenientes tanto de ação social, pois todo conhecimento é produzido socialmente, quanto de uma ação do indivíduo de buscar esse conhecimento, como aborda Tardif (2014). E percebemos ao longo das entrevistas que muitos dos licenciandos sentem prazer em estudar a ciência geográfica: 
A geografia me cativou, me apaixonou, fez com que eu amasse, mudou praticamente tudo (Esmeralda, licencianda do $7^{\circ}$ período do IFPE, 2019). Escolhi a disciplina por amorosidade com a disciplina e com ser professora. (Lua, licencianda do $3^{\circ}$ período da UFPE, 2019).

Aqui salientamos que todos(as) os(as) licenciandos(as) que fizeram parte da pesquisa, na entrevista semiestruturada, evidenciaram o emocional muito ligado à ciência geografia, mas nem todos esses(as) estudantes demonstraram uma ligação de amorosidade com as disciplinas de cunho pedagógico que compõem a licenciatura, apesar de todos(as) eles(as) afirmarem que querem ser professores(as) de geografia e que a escolha profissional era a desejada. Vemos isso na fala da licencianda Aurora, quando questionada sobre sua percepção acerca das disciplinas de cunho pedagógico do curso:

\section{Tem que ter uma renovação desse currículo, a gente percebe, o que minha turma mais que majoritariamente fala é que as disciplinas são diferentes, têm nomes diferentes, mas são praticamente assim todas iguais de conteúdo. Exemplo Saviani, a gente lê vários textos de Saviani iguais em várias disciplinas, e isso atrapalha que a gente tenha prazer mesmo de estudar. (Aurora, licencianda do $6^{\circ}$ período da UFPE, 2019).}

Apesar da licencianda Aurora elencar que deseja ser professora, ela não encontra prazer ao estudar as disciplinas de cunho pedagógico, alegando que os saberes elencados nessas disciplinas acabam por se repetirem ao longo do curso. Isso nos leva a pensar que: "muitos processos de ensino em curso na universidade não passam de meras reproduções de mini palestras ou reunião de um número determinado de pessoas ouvindo uma delas expor determinado assunto" (PIMENTA; ANASTASIOU, 2002, p. 204).

Acreditamos e defendemos o fato de que a licenciatura em geografia deve possuir sua matriz curricular com disciplinas de cunho pedagógico, como atualmente ocorre com os currículos das licenciaturas em geografia do IFPE e da UFPE. Mas identificar a fala da licencianda Aurora acima, assim como de alguns outros entrevistados, que ressaltaram o distanciamento existente entre as disciplinas pedagógicas e as disciplinas do campo da geografia, leva-nos a pensar sobre quais práticas pedagógicas vêm permeando essa licenciatura e por que, apesar de a licenciatura em geografia, hoje, no ano de 2019, possuir uma matriz curricular em que os saberes disciplinares e pedagógicos são vistos em consonância, ainda apresenta uma "desarticulação" desses saberes. Mas, no momento, não iremos entrar nessa discussão.

O campo semântico das representações sociais dos(as) licenciandos(as) em geografia permitiu-nos identificar que a representação social do ser professor(a) de geografia se encontra alicerçada na categoria disciplinar. E, ao analisarmos a árvore de similitude, identificamos também que a representação do ser professor(a) de geografia circunscreve-se nessa categoria.

\section{CONCLUSÕES}

Neste artigo, procuramos apresentar as representações sociais dos licenciandos de geografia sobre o ser professor(a) dessa disciplina. Identificamos que as representações sociais dos sujeitos que participaram da nossa amostra encontram-se alicerçadas na categoria disciplinar.

Essa categoria se origina nas representações que os(as) licenciandos(as) possuem do ser professor(a) de geografia, que estão ligadas aos saberes disciplinares, aos saberes da ciência geográfica. Também observamos outra categoria com bastante força: a pedagógica (composta pelo ato de ensinar e educar, entre outros).

Contudo, identificamos, ainda, a categoria afetiva (composta por diversos sentimentos que são atribuídos à docência pelos licenciandos) e a categoria profissional, constituída por representações profissionais.

A preocupação com a formação de professores(as) vem sendo requerida como condição para a melhoria da qualidade da 
educação brasileira e, cada vez mais, tem ganhado espaço nas políticas educacionais.

Nesse sentido, as representações sociais do ser professor(a) de geografia são imbuídas de diferentes saberes, que são fruto tanto da formação inicial dos licenciandos quanto de suas percepções de mundo e experiências do cotidiano.

As análises aqui apresentadas possibilitaram compreender a relação da construção da identidade profissional docente, com base nas representações sociais evidenciadas no estudo.

A docência, assim, é construída de forma processual, como destaca Pimenta (2005, p. 18), "mas é um processo de construção do sujeito historicamente situado". Como o ser professor(a) de geografia é um construto, imbuído dos mais diversos saberes do devir do(a) licenciando(a) e posteriormente do(a) docente em geografia, as representações sociais do ser professor(a) de geografia podem sofrer as mais diversas transformações ao longo da vida do(a) profissional de educação.

Dessa forma, os resultados aqui encontrados não esgotam as discussões acerca das representações sociais do ser professor(a) de geografia. Pelo contrário, os dados aqui encontrados são propositivos para o desenvolvimento de novas pesquisas que pensem a respeito dessa formação inicial ou da profissão docente, que, como vimos ao longo de todo o trabalho, é uma profissão complexa.

\section{REFERÊNCIAS}

ABRIC, J. C. A abordagem estrutural das representações sociais. In: MOREIRA, A. S. P.; OLIVEIRA, D. C. (Org.). Estudos interdisciplinares de Representação Social. Goiânia: AB, 1998.

BARDIN, L. Análise de Conteúdo. Lisboa: Ed. 70, 1977.

BRASIL. Resolução CNE/CP № 2, de 1ㅇ de julho de 2015. Brasília, 2015.
CAMARGO, B. V.; JUSTO, A. M. IRAMUTEQ: Um Software Gratuito para Análise de Dados Textuais. Temas em Psicologia, Ribeirão Preto, v. 21, n. 2, p. 513-518, 2013. Disponível em: DOI:10.9788/TP2013.2-16

CHAMON, Edna Maria Querido de Oliveira; GUARESCHI, Pedrinho Arcides; CAMPOS, Humberto Faria. Textos e debates em representação social. Org. Edna Maria Querido de Oliveira Chamon. Porto Alegre: Abrapso, 2014.

FREIRE, P. Pedagogia da autonomia: saberes necessários à prática educativa. 52. ed. Rio de Janeiro: Paz e Terra, 2015.

JODELET, Denise. Representações Sociais: um domínio em expansão. In: JODELET, Denise. (Org.). As representações Sociais. Rio de Janeiro: Eduerj, 2001. p. 17-29.

MOSCOVICl, S. A Representação Social da

Psicanálise. Rio de Janeiro: Zahar, 1978.

PIMENTA, Selma Garrido; ANASTASIOU, Léa das Graças Camargo. Docência no ensino superior. São Paulo: Cortez, 2002.

PIMENTA, Selma Garrido. Saberes pedagógicos e atividade docente. 4. ed. São Paulo: Cortez, 2005.

SANTOS, M. Por uma outra globalização: do pensamento único à consciência universal. Rio de Janeiro: Record, 2006.

TARDIF, Maurice. Saberes docentes e formação profissional. Petrópolis: Vozes, 2014.

VESENTINI, José William. Educação e ensino da geografia: instrumentos de dominação e/ou de libertação. In: CARLOS, Ana Fani A. (Org.). A geografia na sala de aula. 8. ed. São Paulo: Contexto, 2008. p. 14-33. 